\title{
ЭКОЛОГО-ГЕОХИМИЧЕСКАЯ ОЦЕНКА СОСТОЯНИЯ ПОЧВЕННОГО ПОКРОВА ТЕРРИТОРИИ СОРСКОГО ГОРНОГО-ОБОГАТИТЕЛЬНОГО КОМБИНАТА (РЕСПУБЛИКА ХАКАСИЯ)
}

\author{
Белошейкина Александра Васильевна', \\ sashechka_0704@mail.ru \\ Таловская Анна Валерьевна², \\ talovskaj@yandex.ru \\ Язиков Егор Григорьевич2, \\ yazikoveg@tpu.ru \\ 1 Общество с ограниченной ответственностью «ХАКАСТИСИЗ», \\ Россия, 655001, Республика Хакасия, г. Абакан, ул. Крылова, 68А, а/я 139. \\ 2 Национальный исследовательский Томский политехнический университет, \\ Россия, 634050, г. Томск, пр. Ленина, 30.
}

\begin{abstract}
Актуальность работы обусловлена необходимостью изучения воздействия горнодобывающих предприятий на компоненты природной среды. Особенно актуально проведение эколого-геохимической оценки территории Сорского горно-обогатительного комбината (Республика Хакасия), одного из главных предприятий России по добыче и переработке медно-молибденовых руд.

Цель: оценка техногенной геохимической трансформации почв в зоне влияния медно-молибденового месторождения для разработки рекомендаций по проведению производственного геоэкологического мониторинга.
\end{abstract}

Методы: масс-спектрометрия с индуктивно связанной плазмой (ИСП-МС).

Результаты. Установлены уровни накопления тяжёлых металлов 1, 2 и 3 класса опасности в поверхностном горизонте почв и по глубине почвенного разреза (0-5, 5-20, 20-40 см) вблизи промышленной площадки (карьер и сопутствующие объекты), отвалов вскрышных пород, хвостохранилища, а также на удалении от них за пределами земельного отвода и санитарно-защитной зоны и на территории г. Сорска. Техногенная геохимическая специализация поверхностного слоя почв проявляется в повышенных уровнях накопления Мo (2-126 фонов), Си (1,5-5 фонов), Mn (7-11 фонов), Cd, Pb, Ni, As, Zn (1,5-5 фоноов). Содержание As превышает ПДК от 2 до 10 раз. Поверхностный слой почв вблизи промплощадки имеет Mo-Mn-Cu-Cd-W-Pb геохимическую специализацию, в северовосточном направлении от промплощадки и отвалов вскрышных пород - Mo-Mn-Ni- W, хвостохранилища - Mn-Mo-Ni, mерритория 2. Сорска - Mo-Mn-W-Pb-Cd. Накопление Мо происходит в основном в поверхностном горизонте почв (0-5 см) и обусловлено преимущественно природными (геологическое строение) и техногенными (аэрогенное загрязнение во время буровзрывных работ, ветровая эрозия отвалов) фракторами. В большинстве пунктов отбора почв выявлена закономерность увеличения содержания $\mathrm{Ni}, \mathrm{As}, \mathrm{Cd}$, Sr, Cr, Сu u Zn по глубине почвенных разрезов от 0-5 до 20-40 см, что отражает специфиику геологического строения территории. Выявлен высокий уровень загрязнения почв тяжёлыми металлами относительно фоновых значений в районе промышленной площадки, вблизи отвалов, а также на территории е. Сорска. Низкий уровень загрязнения определён в районе расположения хвостохранилища. В качестве рекомендаций для производственного геоэкологического мониторинга предложен перечень контролируемых тяжелых металлов.

Выводы. Приоритетными элементами-индикаторами состояния почвенного покрова являются Mo, Cu, W, Cd, Pb, Ni, As, Zn. Учитьвая фракт, что исследования приводятся на территории медно-молибденового месторождения, содержание в почвенном покрове Мо и Си неизбежно. При техногенной трансфоормации поверхностных горизонтов почв увеличиваются концентрации тяжельх металлов. Наибольшую техногенную нагрузку испытывают почвы в зоне влияния разработки карьера, отвалов. Увеличение содержание химических элементов с глубинной почвенных разрезов связано с особенностью геологического строения территории. Высокие уровни накопление элементов в верхнем горизонте почв связано с аэротехногенным загрязнением территории за счет переноса загрязняющих компонентов от основных антропогенных источников.

\section{Ключевые слова:}

Почва, горнодобывающее предприятие, месторождение, тяжелые металлы, масс-спектрометрия с индуктивно-связанной плазмой, эколого-геохимическая оценка.

\section{Введение}

Добыча природных минеральных ресурсов приводит к негативному воздействию на состояние окружающей среды. Приоритетным в разработке твердых полезных ископаемых является открытый способ добычи, который оказывает крайне неблагоприятное влияние на экологическое состояние компонентов природной среды. Возникает необходимость исследования воздействия предприятий горнодобывающей промышленности на окружающую среду. Особо актуально осуществлять экологическую оценку состояния почвенного покрова, поскольку при добыче полезных ископаемых происходит существенное механическое разрушение и химическое загрязнение почвы $[1,2]$.
Почвенный покров является идеальной депонирующей средой для оценки воздействия горнодобывающих предприятий, что показано во многих российских [1-4] и зарубежных [5-14] работах. С одной стороны, почвенный покров наследует химический состав материнской породы, с другой стороны, почвы накапливают продукты техногенеза. При разработке месторождений в окружающую среду поступают различные химические элементы, в том числе тяжелые металлы, содержащиеся в рудах и сопутствующих породах. Эти элементы рассеиваются, мигрируют в ландшафтах и накапливаются в токсичных концентрациях в компонентах природной среды [3].

Известны исследования о геохимической трансформации почв в районе добычи медно-молибденовых руд в 
Монголии [4]; особенностях миграции тяжелых металлов в системе «почва-растительность» на месторождениях по добычи цинковых, медно-цинковых и свинцовых руд на юге Марокко [9]; о миграции металлов в донных отложениях в зоне воздействия железо-медно-свинцового месторождения в Германии [10]; об уровнях накопления металлов в почвах, воздухе, воде, рисе и в других продуктах питания для оценки риска здоровью населения, проживающего вблизи свинцово-цинкового месторождения на юге Китая [11].

Сорский горно-обогатительный комбинат (ГОК) - это одно из главных предприятий России по добыче и переработке медно-молибденовых руд, расположенное в Республике Хакасия (105 км от г. Абакана), вблизи г. Сорска. Месторождение гидротермальное, средне-высокотемпературное, сформировано в результате прерывистого стадийного развития рудного процесса. Главная масса руд связана с кварцевыми жилами и прожилками с промышленным содержанием молибдена и меди. Рудные минералы представлены молибденитом, халькопиритом, пиритом, галенитом, сфалеритом, гематитом, магнетитом и рутилом.

Природно-техногенная система месторождения включает карьер, горно-обогатительный комбинат и источники, связанные с процессом добычи (хвостохранилище, отвалы, пульпопроводы и др.).

Выбросы пыли и различных газов (оксид азота, диоксид азота, оксид углерода, сернистый ангидрит и др.) в атмосферный воздух поступают при буровзрывных работах в карьере; транспортировке руды на БЕЛАЗах; от продуктов сгорания топлива технологического транспорта и оборудования; от вентиляционных выбросов обогатительной фабрики и других производств; выхлопных газов автомобильного транспорта; с поверхности карьера, отвалов и хвостохранилища.

При массовых буровзрывных работах в карьере образуется пылегазовое облако значительного объема, которое может подниматься на сотни и тысячи метров над землей и распространяться на значительные расстояния от места взрыва.

Во время ветровой эрозии отвалов вскрышных пород происходит также запыление атмосферного воздуха, интенсивность этой эрозии связана с особенностями влажности, фракционного состава горной массы, метеорологических параметров (скорость ветра, влажности и др.) [15]. В местах расположения отвалов происходит загрязнение подземных вод за счет инфильтрационных процессов.

Одним из источников загрязнения также является хвостохранилище, размещенное в перегороженной плотиной долине р. Сора. Участки хвостохранилища вследствие неизбежных инфильтрационных процессов являются очагами химического загрязнения поверхностных и подземных вод. Хвосты мокрого обогащения являются преимущественно тонкопорошковым материалом, сильно пылящим в сухом состоянии. В составе пульпы определен кварц, полевой шпат, флюорит и сульфиды.

В районе распространены черноземы и намытые каштановые почвы. Ухудшение качества почвенного покрова также является результатом разработки месторождения. В результате ведения карьерных работ, складирования отходов обогащения руды, размещения объектов горного производства, транспортных коммуникаций происходит отчуждение земель, изменение рельефа, а также техногенное преобразование и загрязнение почв, формирование геохимических аномалий в почвенном покрове.

Химическое загрязнение почвенного покрова является результатом осаждения из атмосферного воздуха пыли, содержащей тяжелые металлы, и других веществ. В результате в почвенный покров поступают и концентрируются тяжелые металлы 1, 2, 3 класса опасности, наслаивающиеся на природные геохимические аномалии. Изучение фондовых материалов показало, что при проведении производственного геоэкологического мониторинга почвенного покрова (фондовые материалы) в период с 2010 по 2014 гг. основное внимание было уделено изучению небольшого перечня тяжёлых металлов, таких как цинк, медь, свинец, кобальт, кадмий, никель, молибден, мышьяк, фтор водорастворимый и ртуть, в горизонтах почв (0-5 и 5-20 см). В этот период были установлены превышения содержания цинка, меди и свинца относительно ПДК Определено, что реакция почвенной среды изменяется от нейтральной до слабощелочной. Средневзвешенное содержание гумуса составляет 5,17 \% (почва среднегумусная), запасы гумуса в слое 0-20 см около 105 т/га. Содержание нитратного азота в почве очень низкое, подвижного фосфора - от очень низкого до очень высокого, обменного калия - от очень низкого до повышенного.

Учитывая факты локализации различных рудопроявлений, а также состав добываемых руд и вмещающих пород, необходимо изучение более широкого спектра тяжелых металлов в почвах и закономерностей изменения их концентрирования по глубине почвенных разрезов в зоне влияния основных источников загрязнения месторождения для оценки степени техногенной трансформации почвенного покрова, что и явилось целью настоящей работы.

\section{Методика исследования}

Для эколого-геохимической оценки состояния почвенного покрова на территории Сорского медномолибденового месторождения было выбрано 6 ключевых участков: ключевой участок № 1 - промышленная площадка в районе расположения карьера; участок № 2 северо-восточное направление от промплощадки; участок № 3 - восточное направление от отвала № 8; участок № 4 - территория г. Сорска и вблизи него; участок № 5 - юго-западное направление от хвостохранилища; участок № 6 - северо-западное направление от хвостохранилища (рисунок). Ключевые участки располагались на векторах, которые учитывали главенствующее направление ветра (юго-западное). Пробы были отобраны вблизи объектов, на границах земельного отвода, расчетной санитарно-защитной зоны и за их пределами, а также в существующих пунктах геоэкологического мониторинга. Расстояние между точками на каждом участке составляло около 200 м, между первой и последней точками - около 1 км.

Для получения данных о региональных фоновых значениях отобраны пробы на фоновом участке, 5 км на юго-запад от объекта изучения, со схожими почвенными и геологическими условиями.

Отбор проб, их транспортировка и подготовка в лаборатории к анализу осуществляли согласно нормативным 
документам [16-18]. В каждом пункте отбор почвы проводили методом конверта со сторонами $1 \times 1$ м. Из пяти точечных проб, масса каждой из которых была 0,5 кг, формировали объединенную пробу массой не менее 2,5 кг, путем смешивания пяти точечных проб. Кроме того, для определения миграции химических элементов по глубине отбирали пробы в почвенных разрезах по интервалам: 0-5, 5-20 и 20-40 см (табл. 1). Отбор проводили инструментом, не содержащим металлов. Всего было отобрано 64 пробы почв.

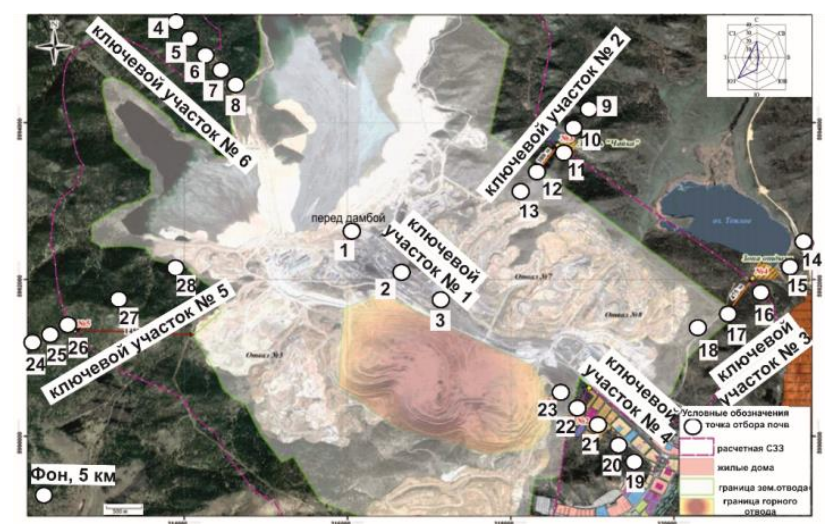

Рисунок. Схема отбора проб почв на территории ООО «Сорский ГОК» и в зоне его влияния

Figure. Scheme of soil sampling within territory of $O O O$ «Sorsk mining and processing industrial complex» and its impacted area

Подготовка проб включала несколько этапов: в начале проводили просушивание проб при комнатной температуре; затем удаление крупных включений и ручное растирание; после просеивание через сита (2,5 и 1 мм); далее фракцию менее 1 мм измельчали до размера 0,074 мм на микровиброистирателе.

Валовое содержание тяжелых металлов 1 класса (As, $\mathrm{Cd}, \mathrm{Pb}, \mathrm{Zn}), 2$ класса (Co, Ni, Cu, Mo, Cr, Sb) и 3 класса опасности (Ba, Sr, Mn, W, V) в пробах были определены методом масс-спектрометрии с индуктивно связанной плазмой (ИМП-МС) в аккредитованной лаборатории ХАЦ «Плазма» (г. Томск).

Методика обработки аналитических результатов включала в себя расчет эколого-геохимических показателей [16, 19-21].

Коэффициент опасности $\left(\mathrm{K}_{0}\right)$ :

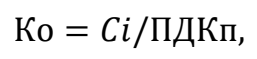

где $\mathrm{Ci}$ - содержание элемента, мг/кг; ПДК - предельнодопустимая концентрация валовых содержаний элементов для пахотного слоя почвы, мг/кг (ГН 2.1.7.2041-06).

Коэффициент концентрации (КК):

$$
\mathrm{KK}=\mathrm{Ci} / \mathrm{C} \phi,
$$

где Сф - содержание элемента в фоновой пробе, мг/кг.

Суммарный показатель загрязнения (СПЗ):

$$
\text { СПЗ }=\sum \text { КК }-(n-1),
$$

где $n$ - число элементов с КК $\geq 1,5$.

Градация степени загрязнения почвенного покрова по СП3: <16 - низкая; 16-32 - средняя; 32-128 - высокая; $\geq 128$ - очень высокая.

\section{Результаты и их обсуждение}

Анализ данных показал, что в поверхностном слое (0-5 см) почвенного покрова на всех изучаемых ключевых участках содержание As превышает ПДК п 2 до 4 раз, а концентрация $\mathrm{V}$ немного выше ПДК в пробах с ключевого участка № 5 (юго-западное направление от хвостохранилища) (табл. 2). Содержание $\mathrm{Mn}, \mathrm{V}, \mathrm{Pb}$ и $\mathrm{Sb}$ в почвах не превышает ПДК для валового содержания элементов. Выявлено повышенное содержание $\mathrm{As}, \mathrm{Cd}, \mathrm{Zn}$, $\mathrm{Mo}, \mathrm{Cu}$ в пробах (0-5 см) с ключевого участка № 1 (территории промплощадки) относительно таковых в пробах с других ключевых участков (табл. 2).

Относительно фоновых концентраций в поверхностном слое почвы (0-5 см) на всех изучаемых ключевых участках устанавливается повышенное накопление $\mathrm{Mo}, \mathrm{Mn}, \mathrm{Cu}, \mathrm{W}$, $\mathrm{Ni}$ (табл. 3). В поверхностном почвенном покрове (0-5 cм) на ключевом участке № 1 специфичными тяжелыми металлами являются $\mathrm{Mo}, \mathrm{Mn}, \mathrm{Cu}, \mathrm{Cd}, \mathrm{W}, \mathrm{Pb}$, на участке № 2 $\mathrm{Mo}, \mathrm{Mn}, \mathrm{Ni}$, на участке № 3 - Mo, Mn, W, на участке № 4 $\mathrm{Mo}, \mathrm{Mn}, \mathrm{W}, \mathrm{Pb}, \mathrm{Cd}$, на участке № 5 - Mn, Mo, Ni, на участке № 6 - Mn, Mo, Ni (табл. 3). Данные тяжелые металлы можно рекомендовать для включения в перечень контролируемых показателей в почвенном покрове в рамках производственного геоэкологического мониторинга.

Уровни накопления выделенных специфичных тяжелых металлов в почвенном покрове на каждом ключевом участке формируют различную степень загрязнения. Сравнительный анализ усредненных значений величин суммарного показателя загрязнения на изученных ключевых участках показал, что в поверхностном слое почвы (0-5 cм) с территории ключевого участка № 1 (промышленная площадка) формируется очень высокая; ключевого участка № 4 (вблизи и на территории г. Сорска) - высокая; ключевого участка № 2 (северо-восточное направление от промплощадки) - средняя степень загрязнения (табл. 3). Почвы из ключевого участка 3 (восточная часть от отвала № 8), участка № 5 и 6 (северо-западная и югозападная части от хвостохранилища) характеризуются низкой степенью загрязнения. На всех ключевых участках наибольший вклад в величину СПЗ вносит высокое содержание Мо в почвах относительно фона.

По величине СПЗ в северо-восточном направлении от промплощадки и отвала № 7 (ключевой участок № 2) можно отметить, что в точке № 13 поверхностный слой почвы характеризуются высокой степенью загрязнения, в точке № 10 - средней степенью загрязнения, тогда как в остальных (точки № 9-11) - низкая степень загрязнения.

Специфика элементного состава почвенного покрова связана, с одной стороны, с металлогеническим особенностями месторождения. С другой стороны, вероятно поступление тяжелых металлов в составе пылевых частиц, образующихся во время буровзрывных работ в карьере, погрузочных работах, транспортировки руды, ветровой эрозии поверхности отвалов, хвостохранилища и бортов карьера. На ключевом участке № 4, охватывающем территорию г. Сорска, загрязнение почвенного покрова может быть сформировано за счет дальнего переноса пылевых частиц от источников промплощадки месторождения, а также от объектов, расположенных в г. Сорске и ст. Ербинская, таких как угольная ТЭЦ и печное отопление. 
Таблица 1. Характеристика почвенных разрезов на ключевых участках территории Сорского ГОКа и в зоне его влияния Table 1. Characteristic of soil sections in the sites of study within territory of Sorsk mining and processing industrial complex and its impacted area

\begin{tabular}{|c|c|c|c|c|}
\hline \multirow{2}{*}{$\begin{array}{c}\text { Ключевой } \\
\text { участок } \\
\text { Site of study }\end{array}$} & \multirow{2}{*}{$\begin{array}{c}\text { № точки } \\
\text { отбора } \\
\text { Number of } \\
\text { sampling site } \\
\end{array}$} & \multicolumn{3}{|c|}{ Характеристика почвенного разреза в точке отбора/Characteristic of soil sections in sampling site } \\
\hline & & $0-5 \mathrm{~cm} / \mathrm{cm}$ & $5-20 \mathrm{~cm} / \mathrm{cm}$ & $20-40 \mathrm{~cm} / \mathrm{cm}$ \\
\hline $\begin{array}{l}\text { № } 1 \text { - промыш- } \\
\text { ленная площадка } \\
1 \text { - industrial site }\end{array}$ & $1,2,3$ & $\begin{array}{l}\text { Почво-грунты } \\
\text { soil and subsoil }\end{array}$ & - & - \\
\hline $\begin{array}{l}\text { № } 2 \text { - северо- } \\
\text { восточное } \\
\text { направление от } \\
\text { промплощадки } \\
2 \text { - the north-east } \\
\text { direction from } \\
\text { industrial site }\end{array}$ & 9 & $\begin{array}{l}\text { Намытая темно-каштановая } \\
\text { почва слегка заболоченная, } \\
\text { переувлажненная. Средне- } \\
\text { тяжелый суглинок. Структу- } \\
\text { ра пылевато-комковатая, } \\
\text { непрочная. Горизонт А } \\
\text { Alleviate dark brown soil slightly } \\
\text { waterlogged. Clay loam. The } \\
\text { structure is pulverous, crumbling } \\
\text { soil, undurable. Horizon A }\end{array}$ & $\begin{array}{l}\text { Намытая буро-каштановая почва с } \\
\text { темными отдельностями органи- } \\
\text { ческого вещества. Суглинок. } \\
\text { Структура средне- и мелкокомко- } \\
\text { ватая, непрочная. Горизонт АВ } \\
\text { Alleviate dark brown soil with dark } \\
\text { inclusions of organic matter. Clay } \\
\text { loam. The structure is fine and } \\
\text { ultrafine fine grained soil, undurable. } \\
\text { Horizon AB }\end{array}$ & $\begin{array}{l}\text { Неоднородная бурая каштановая почва. } \\
\text { Структура мелко-ореховато щебнистая с } \\
\text { тонкой фракцией супесчано-суглинистой } \\
\text { составляющей. Горизонт ВД } \\
\text { Heterogeneous reddish brown soil. The } \\
\text { structure is fine, nutty structure, channery } \\
\text { including fine grained fraction of sandy } \\
\text { loam. Horizon AD }\end{array}$ \\
\hline $\begin{array}{l}\text { № } 3 \text { - восточное } \\
\text { направление от } \\
\text { отвала № } 8 \\
3 \text { - the east } \\
\text { direction from } \\
\text { rock dump } 8\end{array}$ & 14 & $\begin{array}{l}\text { Неоднородная каштановая } \\
\text { почва с темными и бурова- } \\
\text { тыми включениями. Струк- } \\
\text { тура комковато-пылеватая с } \\
\text { ореховатостью. Суглинок. } \\
\text { Горизонт } \mathrm{A}_{1} \\
\text { Heterogeneous brown soil with } \\
\text { dark and reddish inclusions. } \\
\text { The structure is pulverous and } \\
\text { the nutty structure. Clay loam. } \\
\text { Horizon } \mathrm{A}_{1}\end{array}$ & $\begin{array}{l}\text { Неоднородная каштановая почва с } \\
\text { темно-бурыми вкраплениями } \\
\text { мелкозема. Ореховатая структура. } \\
\text { Легкий суглинок. Горизонт АВ } \\
\text { Heterogeneous brown soil with dark } \\
\text { and reddish inclusions of fine } \\
\text { grained soil. There is the nutty } \\
\text { structure of soil. Clay loam. Horizon } \\
\text { AB }\end{array}$ & $\begin{array}{l}\text { Неоднородная каштановая почва с темно- } \\
\text { бурыми вкраплениями темных частиц с } \\
\text { переходом к подстилающим породам. } \\
\text { Структура от мелко до крупно-ореховатой } \\
\text { с примесью мелкой щебенки. Горизонт ВД } \\
\text { Heterogeneous brown soil with dark and } \\
\text { reddish inclusions of dark particles of } \\
\text { basement rocks. The structure varies from } \\
\text { fine to coarse, nutty structure with the } \\
\text { inclusions of fine spalls. Horizon BD }\end{array}$ \\
\hline $\begin{array}{l}\text { № } 4 \text { - территория } \\
\text { г. Сорска и вбли- } \\
\text { зи него } \\
4 \text { - Sorsk area }\end{array}$ & 19 & $\begin{array}{l}\text { Намытая темно-каштановая } \\
\text { почва, среднесуглинистая, } \\
\text { непрочная. Структура пыле- } \\
\text { вато-комковатая, суглини- } \\
\text { стая. Горизонт A } \\
\text { Alleviate dark brown soil, } \\
\text { semi-clay loam, undurable. } \\
\text { The structure is dusty and fine } \\
\text { grained soil, clay loam. } \\
\text { Horizon A }\end{array}$ & $\begin{array}{l}\text { Намытая темно-каштановая почва } \\
\text { с темно-серым и частично бурова- } \\
\text { тым оттенком. Средний суглинок. } \\
\text { Структура мелко-средне комкова- } \\
\text { тая с включениями подстилающей } \\
\text { породы, не прочная. Горизонт А } \\
\text { Alleviate dark brown soil with } \\
\text { tincture of dark gray and reddish. } \\
\text { Clay loam. The structure is fine and } \\
\text { ultrafine fine grained soil with the } \\
\text { inclusions of basement rocks, } \\
\text { undurable. Horizon A }\end{array}$ & $\begin{array}{l}\text { Намытая темно-каштановая почва с темно- } \\
\text { серыми и частично буроватыми вкраплени- } \\
\text { ями мелкого щебня подстилающей породы. } \\
\text { Среднетяжелый суглинок слегка заиленный. } \\
\text { Структура мелкокомковато-ореховатая с } \\
\text { включениями щебнистого материала под- } \\
\text { стилающей породы. Горизонт АВ } \\
\text { Alleviate dark brown soil with inclusions of } \\
\text { dark gray and reddish inclusions of sandy } \\
\text { loam. Semi-consolidated clay loam slightly } \\
\text { silty. The structure is fine grained and the } \\
\text { nutty structure with inclusions of basement } \\
\text { rocks spalls. Horizon AB }\end{array}$ \\
\hline $\begin{array}{l}\text { № } 5 \text { - юго- } \\
\text { западное направ- } \\
\text { ление от хвосто- } \\
\text { хранилища } \\
5 \text { - the south-west } \\
\text { direction from } \\
\text { tailings }\end{array}$ & 24 & $\begin{array}{l}\text { Темно-серый чернозем с } \\
\text { буроватым оттенком. Струк- } \\
\text { тура комковато-пылеватая. } \\
\text { Горизонт } \mathrm{A}_{0} \\
\text { Dark gray chernozem with } \\
\text { tincture reddish. The structure } \\
\text { is dusty and fine grained soil. } \\
\text { Horizon } \mathrm{A}_{0}\end{array}$ & $\begin{array}{l}\text { Темно-серый чернозем с мелкими } \\
\text { вкраплениями буроватого оттенка. } \\
\text { Структура мелкокомковатая с } \\
\text { opеховатостью. Горизонт } \mathrm{A}_{1} \\
\text { Dark gray chernozem with tincture } \\
\text { reddish. There is fine grained and } \\
\text { nutty structure of soil. Horizon } \mathrm{A}_{1}\end{array}$ & $\begin{array}{l}\text { Смыто-намытый чернозем, неоднород- } \\
\text { ный, темно-серо-бурого цвета. Структура } \\
\text { ореховато-щебнистая. Горизонт АВ } \\
\text { Eroded and alleviate chernozem, } \\
\text { heterogeneous, dark gray and reddish. There } \\
\text { is the nutty and spalls structure of soil. } \\
\text { Horizon AB }\end{array}$ \\
\hline $\begin{array}{l}\text { № } 6 \text { - северо- } \\
\text { западное направ- } \\
\text { ление от хвосто- } \\
\text { хранилища } \\
6 \text { - the north-west } \\
\text { direction from } \\
\text { tailings }\end{array}$ & 4 & $\begin{array}{l}\text { Намытая каштановая неод- } \\
\text { нородная почва с темно- } \\
\text { бурыми включениями ще- } \\
\text { бенки подстилающей поро- } \\
\text { ды. Суглинистая с непроч- } \\
\text { ной структурой. Горизонт А } \\
\text { Heterogeneous alleviate brown } \\
\text { soil with dark reddish } \\
\text { inclusions of basement rocks } \\
\text { spalls. Clay-loam soil with } \\
\text { undurable structure. Horizon A }\end{array}$ & $\begin{array}{l}\text { Неоднородная темно-каштановая } \\
\text { почва с буроватым оттенком. } \\
\text { Структура пылевато-комковато- } \\
\text { ореховатая с мелкой щебенкой. } \\
\text { Суглинок с легким заилеванием. } \\
\text { Горизонт АВ } \\
\text { Heterogeneous alleviate dark brown } \\
\text { soil with tincture of reddish. The } \\
\text { structure is dusty and fine grained and } \\
\text { nutty soil with fine spalls. Clay loam } \\
\text { with slightly silting. Horizon AB } \\
\end{array}$ & $\begin{array}{l}\text { Неоднородная буро-каштановая почва с } \\
\text { крупными включениями подстилающей } \\
\text { породы. Структура комковато-щебнисто- } \\
\text { ореховатая. Горизонт АВД } \\
\text { Heterogeneous alleviate reddish brown soil } \\
\text { with inclusions of basement rocks. The } \\
\text { structure is fine grained, spalled and nutty } \\
\text { soil. Horizon ABD }\end{array}$ \\
\hline Фон/Background & - & $\begin{array}{l}\text { Смыто-намытая темно- } \\
\text { каштановая почва, неоднород- } \\
\text { ная с буроватым оттенком. } \\
\text { Структура комковато- } \\
\text { ореховая суглинистая с при- } \\
\text { сутствием щебня. Горизонт А } \\
\text { Eroded and alleviate brown soil } \\
\text { with tincture of reddish. The } \\
\text { structure is fine grained, spalled } \\
\text { and nutty soil. Horizon A. }\end{array}$ & $\begin{array}{l}\text { Намытая буро-темная каштановая } \\
\text { почва, неоднородная. Присутству- } \\
\text { ют темный вмытый органический } \\
\text { материал и бурый мелкий щебень. } \\
\text { Переходный горизонт АВД } \\
\text { Heterogeneous alleviate reddish } \\
\text { brown soil. There are organic matter } \\
\text { and reddish fine spalls }\end{array}$ & - \\
\hline
\end{tabular}


Известия Томского политехнического университета. Инжиниринг георесурсов. 2020. Т. 331. № 1. 44-53

Белошейкина А.В., Таловская А.В., Язиков Е.Г. Эколого-геохимическая оценка состояния почвенного покрова территории Сорского ...

Таблица 2. Среднее содержание тяжелых металлов в почвенных разрезах ключевых участков на территории и в зоне влияния Сорского ГОК (мг/кг)

Table 2. Heavy metal concentration in soid sections in the sites of study within territory of Sorsk mining and processing industrial complex and its impacted area $(\mathrm{mg} / \mathrm{kg})$

\begin{tabular}{|c|c|c|c|c|c|c|c|c|c|c|c|c|c|c|c|c|c|}
\hline Ключевой участок/Site of study & Глубина, см/Depth, cm & $\mathrm{n}$ & As & $\mathrm{Cd}$ & $\mathrm{Pb}$ & $\mathrm{Zn}$ & Co & $\mathrm{Ni}$ & Mo & $\mathrm{Cu}$ & $\mathrm{Sb}$ & $\mathrm{Cr}$ & $\mathrm{Ba}$ & $\mathrm{V}$ & $\mathrm{W}$ & $\mathrm{Mn}$ & $\mathrm{Sr}$ \\
\hline № 1 & $0-5$ & 5 & 8,3 & 1,9 & 27,7 & 231 & 19,1 & 27,1 & 264 & 300 & 0,8 & 170 & 977 & 91 & 3,1 & 750 & 550 \\
\hline \multirow{3}{*}{ № 2} & $0-5$ & 5 & 3,7 & 0,4 & 14,4 & 142 & 20,6 & 36 & 27,6 & 85,2 & 0,4 & 223 & 848 & 134 & 1,6 & 960 & 536 \\
\hline & $5-20$ & 5 & 4,7 & 0,4 & 13,9 & 138 & 20,9 & 32,2 & 17,6 & 82,8 & 0,4 & 239 & 856 & 146 & 1,6 & 890 & 612 \\
\hline & $20-40$ & 1 & 1,3 & 0,1 & 11,8 & 119 & 24 & 46 & 3,6 & 80 & 0,2 & 208 & 720 & 140 & 1,0 & 750 & 820 \\
\hline \multirow{3}{*}{ № 3} & $0-5$ & 5 & 7,2 & 0,4 & 15,1 & 106 & 13,3 & 17,4 & 12,5 & 64 & 0,8 & 207 & 794 & 99,2 & 2,7 & 834 & 486 \\
\hline & $5-20$ & 5 & 7,3 & 0,3 & 16,3 & 107 & 14,4 & 18,5 & 10,5 & 71,6 & 0,8 & 228 & 804 & 109 & 3,0 & 826 & 500 \\
\hline & $20-40$ & 2 & 9,2 & 0,4 & 17,0 & 130 & 16,3 & 28,9 & 8,3 & 64 & 0,9 & 190 & 805 & 125 & 59,1 & 795 & 520 \\
\hline \multirow{3}{*}{ № 4} & $0-5$ & 5 & 6,9 & 0,8 & 24,2 & 167 & 16,8 & 22,9 & 68,5 & 160 & 0,9 & 234 & 825 & 108 & 4,3 & 832 & 488 \\
\hline & $5-20$ & 5 & 6,4 & 0,8 & 21,6 & 145 & 15,5 & 16,6 & 54,7 & 127 & 0,8 & 192 & 754 & 101 & 2,8 & 792 & 456 \\
\hline & $20-40$ & 2 & 5,8 & 0,8 & 26,2 & 298 & 17,7 & 22,0 & 80,3 & 190 & 0,7 & 235 & 880 & 120 & 4,4 & 800 & 570 \\
\hline \multirow{3}{*}{ № 5} & $0-5$ & 5 & 4,4 & 0,1 & 13,1 & 138 & 24,0 & 30,9 & 3,9 & 62 & 0,4 & 226 & 934 & 166 & 1,5 & 1094 & 650 \\
\hline & $5-20$ & 5 & 5,1 & 0,1 & 14,1 & 138 & 23,9 & 32,6 & 3,0 & 64,2 & 0,3 & 202 & 934 & 166 & 1,5 & 978 & 700 \\
\hline & $20-40$ & 2 & 7,1 & 0,2 & 12,8 & 120 & 21,7 & 26,7 & 1,9 & 56 & 0,3 & 161 & 980 & 145 & 1,3 & 840 & 575 \\
\hline \multirow{3}{*}{ № 6} & $0-5$ & 5 & 5,0 & 0,4 & 15,5 & 125 & 18,3 & 28,6 & 4,1 & 49 & 0,5 & 215 & 666 & 120 & 1,5 & 946 & 535 \\
\hline & $5-20$ & 5 & 5,0 & 0,4 & 15,2 & 130 & 18,4 & 29,8 & 2,9 & 44,2 & 0,7 & 216 & 728 & 126 & 1,6 & 950 & 598 \\
\hline & $20-40$ & 2 & 6,2 & 0,4 & 18,5 & 142 & 18,8 & 24,4 & 3,4 & 47,5 & 0,7 & 223 & 770 & 125 & 1,9 & 1010 & 570 \\
\hline \multirow{2}{*}{ Фон/Background } & $0-5$ & 1 & 6,1 & 0,4 & 13,8 & 156 & 23 & 18,1 & 2,1 & 56 & 0,6 & 184 & 740 & 150 & 1,2 & 100 & 580 \\
\hline & $5-20$ & 1 & 10,5 & 0,1 & 6,3 & 159 & 28 & 46 & 1,8 & 69 & 0,8 & 198 & 700 & 180 & 1,6 & 1190 & 480 \\
\hline \multicolumn{3}{|c|}{ ПДК $/ \mathrm{MAC}_{\mathrm{s}}$} & 2 & - & 32 & - & - & - & - & - & 4,5 & - & - & 150 & - & 1500 & - \\
\hline
\end{tabular}

Примечание: наименование ключевых участков см. в табл. 1; ПДК для валового содержания элементов (ГН 2.1.7.2041-06); $n$-количество проб.

Note: name of site of study is shown in Table 1; $M A C_{s}$ is for the total element content in soil (GN 2.1.7.2041-06); $n$ is the number of samples.

Таблица 3. Геохимическая характеристика почвенного покрова (0-5 см) и СПЗ на ключевых участках на территории и в зоне влияния Сорского ГОКа

Table 3. Geochemical characteristics of soil $(0-5 \mathrm{~cm})$ and total pollution factor (TPF) in the sites of study within territory of Sorsk mining and processing industrial complex and its impacted area

\begin{tabular}{|c|c|c|c|c|c|}
\hline \multirow{2}{*}{$\begin{array}{c}\text { Ключевой } \\
\text { участок } \\
\text { Site of study }\end{array}$} & \multicolumn{4}{|c|}{$\begin{array}{l}\text { Уровни коэффициента концентрации относительно фона } \\
\text { Levels of coefficient concentration relatively to background }\end{array}$} & \multirow{2}{*}{$\begin{array}{l}\text { CПЗ } \\
\text { TPF }\end{array}$} \\
\hline & $15-130$ & $5-15$ & $1,5-5$ & $<1,5$ & \\
\hline № 1 & $\begin{array}{c}\text { Mo } \\
(126)\end{array}$ & $\operatorname{Mn}(7,5)$ & $\begin{array}{c}\mathrm{Cu}(5,4), \mathrm{Cd}(4,8), \mathrm{W}(2,5), \mathrm{Pb} \\
(2)\end{array}$ & $\begin{array}{c}\mathrm{Ni}(1,5), \mathrm{As}(1,4), \mathrm{Sb}, \mathrm{Ba}(1,3), \mathrm{Zn}(1,5), \mathrm{Cr}, \mathrm{Sr}(0,9), \mathrm{Co}(0,8), \\
\text { V }(0,6)\end{array}$ & 145 \\
\hline № 2 & - & $\begin{array}{l}\text { Mo (13), Mn } \\
\quad(9,6)\end{array}$ & $\mathrm{Ni}(2)$ & $\begin{array}{c}\mathrm{Cu}(1,3), \mathrm{W}(1,3), \mathrm{Cd}, \mathrm{Pb}, \mathrm{Cr}, \mathrm{Ba}(1), \mathrm{Zn}, \mathrm{Co}, \mathrm{V}, \mathrm{Sr}(0,9) \\
\mathrm{As}, \mathrm{Sb}(0,6)\end{array}$ & 24 \\
\hline № 3 & - & Mo (6), Mn (8) & $\mathrm{W}(2)$ & As, $\mathrm{Sb}(1,2), \mathrm{Cd}, \mathrm{Cu}, \mathrm{Ba}, \mathrm{Pb}, \mathrm{Ni}(1), \mathrm{Sr}(0,8), \mathrm{Co}(0,6), \mathrm{V}(0,7)$ & 15 \\
\hline № 4 & Mo (32) & $\operatorname{Mn}(8,3)$ & $\mathrm{W}(3,5), \mathrm{Cd}, \mathrm{Pb}(2)$ & $\mathrm{Ni}(1,3), \mathrm{As}, \mathrm{Zn}, \mathrm{Ba}(1), \mathrm{Co}, \mathrm{V}, \mathrm{Sr}(0,7)$ & 47 \\
\hline № 5 & - & Mn (10) & Mo (1,9), Ni $(1,7)$ & $\begin{array}{c}\mathrm{Cr}, \mathrm{W}(1,2), \mathrm{Cd}, \mathrm{Pb}(1), \mathrm{Cu}, \mathrm{Ba}, \mathrm{Sr}(0,9), \mathrm{As}, \mathrm{Zn}, \mathrm{Co}, \mathrm{Sb}, \\
\mathrm{V}(0,8)\end{array}$ & 14 \\
\hline № 6 & - & - & $\operatorname{Mn}(9,5), \operatorname{Mo}(2), N i(1,6)$ & $\mathrm{W}, \mathrm{Cr}(1,2), \mathrm{Cd}, \mathrm{Pb}(1), \mathrm{Cu}, \mathrm{Sr}(0,9), \mathrm{As}, \mathrm{Zn}, \mathrm{Co}, \mathrm{V}(0,8)$ & 12 \\
\hline
\end{tabular}

Примечание: наименование ключевых участков см. в табл. 1.

Note: name of site of study is shown in Table 1.

Низкая степень загрязнения на ключевых участках № 5 и 6 может быть обусловлена тем, что эти участки расположены в направлении, противоположном преобладающему направлению ветра, соответственно осуществляется минимальный перенос загрязняющих веществ от источников.
Анализ распределения тяжелых металлов по глубине почвенного разреза на ключевом участке № 2 показал преимущественное накопление $\mathrm{As}, \mathrm{Cr}, \mathrm{Ba}, \mathrm{V}, \mathrm{Sr}$ в интервале 5-20 см, Zn, Ni, Mo, Mn, Cu - в поверхностном 0-5 см, Co, $\mathrm{Ni}, \mathrm{Sr}$ - в интервале 20-40 cм, а распределение остальных элементов существенно не изменяется (табл. 2). Деталь- 
ный анализ распределения элементов в точке № 9 (600 м от границы земельного отвода в северо-восточном направлении от промплощадки) показал сохранение закономерностей уменьшения концентрации $\mathrm{Mo}, \mathrm{Cu}, \mathrm{Mn}$ и увеличения содержания Ni по глубине почвенного разреза от поверхностного до нижнего интервала (табл. 4) для всего ключевого участка № 2 .

На ключевом участке № 3 выявлено в интервале от 0-5 до 20-40 см увеличение с глубиной содержания в пробах $\mathrm{As}, \mathrm{Pb}, \mathrm{Zn}, \mathrm{Co}, \mathrm{Ni}, \mathrm{Sb}, \mathrm{Cu}, \mathrm{Sr}$ и уменьшение Mo, Ba, V, Mn (табл. 2). Обращает внимание высокое содержание W в пробе интервала 20-40 см. В точке отбора проб № 14 (600 м от границы земельного отвода) концентрация Zn, $\mathrm{Cu}, \mathrm{W}$ и $\mathrm{Sr}$ увеличивается, а Мо - уменьшается в интервалах от 0-5 до 20-40 см, указывая на общую тенденцию для ключевого участка № 3 .

В пробах с территории ключевого участка № 4, в г. Сорске, накопление $\mathrm{Mo}, \mathrm{Cu}, \mathrm{Cr}, \mathrm{Ba}$ близко как в поверхностном (0-5 см), так и в нижнем интервале (20-40 см) разреза. Для почв этого ключевого участка и в точке № 19 отмечается общая закономерность увеличение содержания Zn по глубине почвенного разреза (табл. 2, 4).

В районе размещения хвостохранилища (ключевые участки № 5 и 6) определено повышенное накопление $\mathrm{Ni}$, $\mathrm{Mo}, \mathrm{Cu}, \mathrm{Ba}$ в поверхностном почвенном слое, а содержание As увеличивается по глубине почвенного разреза. В почвенном разрезе ключевого участка № 6 и в точке № 4 (800 м от границы земельного отвода) увеличивается накопление $\mathrm{Zn}$ и $\mathrm{Sr}$ к глубинным слоям почвы. В точке №24 (1 км от границы земельного отвода) содержание Мо и $\mathrm{Cu}$ снижается с глубиной в почвенном разрезе.
В целом отмечается общая закономерность уменьшения уровней накопления Мо и $\mathrm{Cu}$ в почвенных разрезах с глубиной на всех ключевых участках, за исключением участков 2 и 5, в почвах которых содержание $\mathrm{Cu}$ не изменяется по глубине. Закономерность распределения Мо не отличается от фоновой почвы, что нельзя сказать о $\mathrm{Cu}$.

Характер распределения тяжелых металлов в почвенных разрезах на ключевых участках может свидетельствовать о преимущественном аэротехногенном поступлении элементов, а также отражать особенности геологического строения. Вероятно, повышенное содержание химических элементов в почвенных горизонтах нижних интервалов (20-40 см) связано с особенностью геологического строения территории месторождения. Металлогенические особенности почвообразующих пород могут оказывать влияние на концентрирование тяжелых металлов в почвах. Согласно результатам ранее проведенных исследований, в составе руд месторождения содержатся $\mathrm{Mo}, \mathrm{Cu}, \mathrm{As}, \mathrm{Cd}, \mathrm{Sb}, \mathrm{Co}, \mathrm{V}, \mathrm{Pb}, \mathrm{Ba}$ и другие микроэлементы (геологические отчеты предприятия).

Разработка карьера, погрузочные работы, ветровой перенос с бортов карьера, поверхности отвалов и хвостохранилища усиливают аэрогенное загрязнение территории, что может приводить к высокому накоплению тяжелых металлов в поверхностном слое почв. В ранее проведенных исследованиях установлено, что в отвалах вскрышных пород содержатся $\mathrm{Mo}, \mathrm{Cu}, \mathrm{Zn}$ и $\mathrm{Pb}$ (экологические отчеты предприятия). В двух пробах шлама хвостохранилища ранее нами были определены высокие концентрации Мо (200 г/т), Cu (150-200 г/т), Sr (600 г/т), $\mathrm{Cr}(100-150$ г/T), V (150-200 г/T), Ni (20 г/T).

Таблица 4. Распределение содержания тяжельх металлов в почвенных разрезах в точках на ключевых участках на территории и в зоне влияния Сорского ГОК (мг/кг)

Table 4. Distribution of heavy metal concentration in soil sections in the sampling sites of study within territory of Sorsk mining and processing industrial complex and its impacted area $(\mathrm{mg} / \mathrm{kg})$

\begin{tabular}{|c|c|c|c|c|c|c|c|c|c|c|c|c|c|c|c|c|c|c|}
\hline $\begin{array}{c}\text { Ключевой } \\
\text { участок } \\
\text { Site of } \\
\text { study }\end{array}$ & $\begin{array}{c}\text { № точки } \\
\text { отбора } \\
\text { Number } \\
\text { of } \\
\text { sampling } \\
\text { site }\end{array}$ & $\begin{array}{c}\text { Расстояние от } \\
\text { земельного } \\
\text { отвода, км } \\
\text { Distance from } \\
\text { land allotment, } \\
\text { km }\end{array}$ & 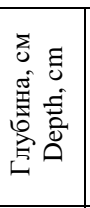 & As & $\mathrm{Cd}$ & $\mathrm{Pb}$ & $\mathrm{Zn}$ & Co & $\mathrm{Ni}$ & Mo & $\mathrm{Cu}$ & $\mathrm{Sb}$ & $\mathrm{Cr}$ & $\mathrm{Ba}$ & V & W & $\mathrm{Mn}$ & $\mathrm{Sr}$ \\
\hline \multirow{3}{*}{ № 2} & \multirow{3}{*}{9} & \multirow{3}{*}{0,6} & $0-5$ & 1,3 & 0,3 & 11,8 & 136 & 23 & 36 & 7,8 & 90 & 0,2 & 225 & 830 & 130 & 1,0 & 1010 & 650 \\
\hline & & & $5-20$ & 0,5 & 0,3 & 12 & 173 & 25 & 43 & 2,7 & 94 & 0,2 & 272 & 750 & 160 & 1,1 & 820 & 770 \\
\hline & & & $20-40$ & 1,3 & 0,1 & 11,8 & 119 & 24 & 46 & 3,6 & 80 & 0,2 & 208 & 720 & 140 & 1,0 & 750 & 820 \\
\hline \multirow{3}{*}{ № 3} & \multirow{3}{*}{14} & \multirow{3}{*}{0,6} & $0-5$ & 6,7 & 0,3 & 16,9 & 94 & 13,1 & 16,2 & 7,4 & 38 & 0,8 & 212 & 800 & 110 & 2,1 & 820 & 530 \\
\hline & & & $5-20$ & 5,8 & 0,3 & 14,5 & 89 & 12,6 & 7,1 & 5,7 & 39 & 0,7 & 150 & 860 & 110 & 2,1 & 670 & 580 \\
\hline & & & $20-40$ & 7,5 & 0,3 & 16,9 & 115 & 12,8 & 13,8 & 5,5 & 34 & 0,7 & 153 & 810 & 110 & 2,1 & 640 & 580 \\
\hline \multirow{3}{*}{ № 4} & \multirow{3}{*}{19} & \multirow{3}{*}{ г. Сорск/Sorsk } & $0-5$ & 5,7 & 0,6 & 24 & 173 & 15 & 19,2 & 29 & 110 & 0,9 & 338 & 1008 & 130 & 3,2 & 800 & 600 \\
\hline & & & $5-20$ & 3,8 & 0,4 & 16,8 & 130 & 14,6 & 11,1 & 12,3 & 58 & 0,7 & 283 & 790 & 120 & 2,9 & 680 & 560 \\
\hline & & & $20-40$ & 5,7 & 0,4 & 17,3 & 380 & 15,9 & 30 & 8,5 & 40 & 0,6 & 290 & 810 & 130 & 5,6 & 650 & 540 \\
\hline \multirow{3}{*}{ № 5} & \multirow{3}{*}{24} & \multirow{3}{*}{1,0} & $0-5$ & 5,5 & 0,1 & 11,9 & 136 & 19,2 & 11,5 & 4,2 & 55 & 0,4 & 205 & 820 & 120 & 1,1 & 1170 & 470 \\
\hline & & & $5-20$ & 5,4 & 0,2 & 12,6 & 137 & 22 & 39 & 1,7 & 57 & 0,4 & 159 & 810 & 150 & 1,3 & 1140 & 490 \\
\hline & & & $20-40$ & 8,5 & 0,01 & 12 & 147 & 24 & 38 & 1,9 & 64 & 0,5 & 157 & 840 & 150 & 1,2 & 1090 & 490 \\
\hline \multirow{3}{*}{ № 6} & & \multirow{3}{*}{0,8} & $0-5$ & 6,6 & 0,5 & 18,1 & 142 & 21 & 43 & 6,6 & 79 & 0,2 & 210 & 700 & 130 & 2 & 1070 & 540 \\
\hline & & & $5-20$ & 6,2 & 0,5 & 16,3 & 152 & 18,7 & 35 & 5,1 & 60 & 0,5 & 263 & 760 & 120 & 1,9 & 1200 & 540 \\
\hline & & & $20-40$ & 5 & 0,5 & 16 & 140 & 18,1 & 37 & 3,8 & 48 & 0,5 & 226 & 780 & 130 & 2,1 & 1090 & 610 \\
\hline \multirow{2}{*}{$\begin{array}{c}\text { Фон } \\
\text { Background }\end{array}$} & & \multirow{2}{*}{5,0} & $0-5$ & 6,1 & 0,4 & 13,8 & 156 & 23 & 18,1 & 2,1 & 56 & 0,6 & 184 & 740 & 150 & 1,2 & 100 & 580 \\
\hline & & & $5-20$ & 10,5 & 0,1 & 6,3 & 159 & 28 & 46 & 1,8 & 69 & 0,8 & 198 & 700 & 180 & 1,6 & 1190 & 480 \\
\hline
\end{tabular}

Примечание: наименование ключевых участков см. в табл. 1 .

Note: name of site of study is shown in Table 1. 


\section{Заключение}

Результаты проведенных исследований показали, что высокий уровень загрязнения тяжелыми металлами 1, 2, 3 класса опасности приходится на почвы промышленной площадки, где производят буровзрывные работы на карьере, погрузочные работы, а также в районе отвалов вскрышных пород и на территории г. Сорска. Низкий уровень загрязнения почв выявлен в районе расположения хвостохранилища. Выявлена общая закономерность уменьшения концентрации Мо и $\mathrm{Cu}$ с глубиной в почвенных разрезах $(0-5,5-20$ и 20-40 см) на всех изучаемых ключевых участках, охватывающих основные объекты загрязнения. За исключением ключевых участков № 2 (северо-восточное направление от промплощадки) и № 5 (юго-западное направление от хвостохранилища), в районе которых содержание $\mathrm{Cu}$ незначительно увеличивается по глубине почвенного разреза.

Поскольку территория месторождения - это изначально рудное тело, то неизбежно содержание в почвенном покрове тяжелых металлов (Mo, $\mathrm{Cu}, \mathrm{Zn}, \mathrm{Pb}$ и другие микроэлементы). Определённую роль в формировании степени загрязнения почвенного покрова играет ветровой перенос загрязняющих веществ, образующихся в резуль-

\section{СПИСОК ЛИТЕРАТУРЫ}

1. Басова И.А., Иоина М.А., Глухова Е.Н. Геоэкологическое состояние почвенного покрова в горнопромышленных регионах // Известия ТулГУ. - 2010. - №. 1. - С. 16-20.

2. Басова И.А., Иватанова Н.П., Копылов А.Б. Оценка экологического состояния почв в регионах с развитой горной промышленностью // Известия ТулГУ. - 2012. - № 1-2. - С. 14-16.

3. Корнеева Т.В., Юркевич Н.В., Саева О.П. Геохимическое моделирование поведения тяжелых металлов в техногенных системах // Известия Томского политехнического университета. Инжиниринг георесурсов. - 2018. - Т. 329. - № 3. - С. 89-101.

4. State of the environment of urban and mining areas in the Selenga Transboundary River Basin (Mongolia Russia) / N.S. Kasimov, N.E. Kosheleva, P.D. Gunin, I.D. Korlyakov, O.I. Sorokina, I.V. Timofeev // Environmental Earth Sciences. - 2016. - V. 75. Is. 1283 . - P. 1-20.

5. A review of soil heavy metal pollution from industrial and agricultural regions in China: Pollution and risk assessment / Q. Yang, Z. Li, X. Lu, Q. Duan, L. Huang, J. Bi // Science of the total environment. - 2018. - V. 642. - P. 690-700.

6. Accumulation, translocation, and assessment of heavy metals in the soil-rice systems near a mine-impacted region / F. Du, Z. Yang, P. Liu, L. Wang // Environmental science and pollution research. 2018. - V. 25 (32). - P. 32221-32230.

7. Evaluation of heavy metal contamination of surface soils in Zarshouran gold district, Northwestern Iran / F. Ghazban, A. Parizanganeh, A. Zamani, S. Baniardalan // International Journal of environmental research. - 2018. - V. 12 (6). - P. 843-860.

8. Possibility of optimized indices for the assessment of heavy metal contents in soil around an open pit coal mine area / R. Sawut, N. Kasim, A. Abliz, H. Li, A. Yalkun, B. Maihemuti, Q.D. Shi // International journal of applied earth observation and geoinformation. 2018. - V. 73. - P. 14-25.

9. Accumulation of heavy metals in metallophytes from three mining sites (Southern Centre Morocco) and evaluation of their phytoremediation potential // L. Midhat, N. Ouazzani, A. Hejjaj, A. Ouhammou, L. Mandi // Ecotoxicology and Environmental Safety. - 2019. - V. 169. - P. 150-160. URL: https://doi.org/10.1016/j.ecoenv.2018.11.009 (дата обращения 01.10.2019). тате добычи руды открытым способом, а также при пылении хвостохранилища, отвалов, бортов карьера.

По итогам проведенных работ рекомендуется оптимизировать систему производственного геоэкологического мониторинга. Эти рекомендации включают в себя предложения по выбору перечня контролируемых тяжелых металлов в почвенном покрове вблизи основных источников загрязнения. По результатам анализа уровней накопления тяжелых металлов в почвах предлагается следующий перечень элементов для периодического контроля в почве $\mathrm{Mo}, \mathrm{Cu}, \mathrm{W}, \mathrm{Cd}, \mathrm{Pb}, \mathrm{Ni}, \mathrm{As}, \mathrm{Zn}$. Выбор данных элементов обусловлен тем, что их содержание в почвах ключевых участков превышает фоновые значения, а содержание As в пробах также превышает ПДК

Авторы выражают благодарность Пашневой Галине Евгеньевне, к.х.н., за консультаиию при описании характеристики почвенных разрезов, Федюниной Нине Викторовне, директору ХАЦ «Плазма», за выполнение химического анализа проб почв.

Работа выполнена в рамках хоздоговорных работ с ООО «Сорский ГОК» (2015 г.). Исследования выполнялись в Начиональном исследовательском Томском политехническом университете в рамках программы повышения конкурентоспособности ТПУ среди ведущих мировых исследовательских иентров.

10. Martin C.W. Trace metal concentrations along tributary streams of historically mined areas, Lower Lahn and Dill River basins, central Germany // Catena. - 2019. - V. 174. - P. 174-183. URL: https://doi.org/10.1016/ j.catena.2018.11.008 (дата обращения 01.10.2019).

11. Different exposure profile of heavy metal and health risk between residents near a $\mathrm{Pb}-\mathrm{Zn}$ mine and $\mathrm{Mn}$ mine in Huayuan county, South China / Y. Du, L. Chen, P. Ding, B. Chen, Y. Duan // Chemosphere. - 2019. - V. 216. - P. 352-364. DOI: 10.1016/j.chemosphere.2018.10.142

12. Distribution, pollution, bioaccumulation, and ecological risks of trace elements in soils of the northeastern Qinghai-Tibet Plateau / L. Li, J. Wu, J. Lu, J. Xu, L. Yang // Ecotoxicology and Environmental Safety. - 2018. - V. 166. - P. 345-353.

13. Impact of the coal mining on the spatial distribution of potentially toxic metals in Farmland tillage soil / F. Li, X. Li, L. Hou, A. Shao // Scientific Reports. - 2018. - V. 8 (1). - P. 14925.

14. Zhang J., Yao D. Geochemical characteristics and source analysis of soil heavy metals in Luling coal mine, northern Anhui Province // IOP Conference Series: Earth and Environmental Science. - 2018. V. 189 (3). - P. 032058.

15. Певзнер М.Е., Костовецкий В.П. Экология горного производства. - М.: Недра, 1990. - 230 с.

16. Методические указания по оценке степени опасности загрязнения почвы химическими веществами № 4266-87. - М.: Мин-во здравоохранения СССР, 1987. - 23 с.

17. ГОСТ 17.4.4.02-84. Охрана природы. Почвы. Методы отбора и подготовки проб для химического, бактериологического, гельминтологического анализа. - М.: Стандартинформ, 2008. - 12 с.

18. ГОСТ 17.4.3.01-83. Охрана природы (ССОП). Почвы. Общие требования к отбору проб. - М.: Стандартинформ, 2008. - 12 с.

19. Сает Ю.Е., Ревич Б.А., Янин Е.П. Геохимия окружающей среды. - М.: Недра, 1990. - 335 с.

20. Язиков Е.Г., Шатилов А.Ю. Геоэкологический мониторинг. Томск: Изд-во ТПУ, 2004. - 276 с.

21. Методические рекомендации по оценке степени загрязнения атмосферного воздуха населенных пунктов металлами по их содержанию в снежном покрове и почве / под ред. Б.А. Ревич, Ю.Е. Саета, Р.С. Смирновой (Утв. 15 мая 1990 г. № 5174-90). М.: ИМГРЭ, 1990. - 7 с. 


\section{Информация об авторах}

Белошейкина А.В., руководитель группы экологии ООО «ХАКАСТИСИЗ».

Tаловская A.B., кандидат геолого-минералогических наук, доцент отделения геологии Инженерной школы природных ресурсов Национального исследовательского Томского политехнического университета.

Язиков $\boldsymbol{E . \Gamma . , ~ д о к т о р ~ г е о л о г о - м и н е р а л о г и ч е с к и х ~ н а у к , ~ п р о ф е с с о р ~ о т д е л е н и я ~ г е о л о г и и ~ И н ж е н е р н о и ̆ ~ ш к о л ы ~ п р и р о д н ы х ~}$ ресурсов Национального исследовательского Томского политехнического университета. 
UDC 631.4:504.5:622.7.013 (571.513)

\title{
ECOLOGICAL AND GEOCHEMICAL ASSESSMENT OF SORSK MINING AND PROCESSING PLANT SOIL COVER (REPUBLIC OF KHAKASSIA)
}

\author{
Aleksandra V. Belosheykina ${ }^{1}$, \\ sashechka_0704@mail.ru \\ Anna V. Talovskaya ${ }^{2}$, \\ talovskaj@yandex.ru \\ Egor G. Yazikov², \\ yazikoveg@tpu.ru \\ 1 LLC «KHAKASTISIZ», \\ 68A, Krylov street, Abakan, Republic of Khakassia, 655001, Russia. \\ 2 National Research Tomsk Polytechnic University, \\ 30, Lenin avenue, Tomsk, 634050, Russia
}

The relevance of the research is caused by the need to study the environmental impact of mining. Ecological and geochemical soil cover assessment of Sorsk mining and processing plant (one of the largest copper-molybdenum mining complexes in Russia) is a high-priority environmental task.

The aims of the research are to assess the geochemical soil transformation affected by copper and molybdenum mining development and give recommendations for industrial geoecological monitoring.

Methods: inductively coupled plasma mass spectrometry (ICP-MS).

Results. The $1^{\text {st }}, 2^{\text {nd }}$ and $3^{\text {rd }}$ hazard classes heavy metals are revealed to be accumulated in the top soils and the soil profile cut in 0-5, 5-20, 20-40 cm depth near the industrial site (open pits and nearby facilities), overburden rock dumps, tailing dumps as well as outside of the land allotment including the sanitary protection zone and the territory of Sorsk. The anthropogenic and geochemical top soil specialization is marked by high Mo content (2-126 background concentrations), Cu content (1,5-5 background concentrations), Mn (7-11 background concentrations), Cd, $\mathrm{Pb}$, $\mathrm{Ni}$, As, Zn (1,5-5 background concentrations). The As concentrations exceed MAC in soil by 2-10 times. Therefore, Mo-Mn-Cu-Cd-W-Pb geochemical specialization is specific for the top soils near the industrial site, as well as Mo-Mn-Ni-W and Mn-Mo-Ni and Mo-Mn-W-Pb-Cd geochemical specializations are typical for the north-east direction from the industrial site and overburden rock dumps and tailing dumps and the territory of Sorsk, respectively. Mo is accumulated in the top soils in 0-5 cm depth due to natural geological structure and anthropogenic (aerogenic pollution caused by drilling-and-blasting or rock wind erosion) factors. For the most soil sampling sites there is a tendency in $\mathrm{Ni}, \mathrm{As}, \mathrm{Cd}, \mathrm{Sr}, \mathrm{Cr}, \mathrm{Cu}$ and $\mathrm{Zn}$ increasing concentrations (in the soil profile 0-5 to 20-40 cm depth) and this specifies the geological territory structure. There is a high soil pollution level comparatively background concentrations within the industrial site, near the overburden rock dumps as well as in the territory of Sorsk. Whereas, a low soil pollution level is revealed near the tailing dumps. The list of elements monitored is recommended for industrial geoecological monitoring.

Conclusions. $\mathrm{Mo}, \mathrm{Cu}, \mathrm{W}, \mathrm{Cd}, \mathrm{Pb}, \mathrm{Ni}, \mathrm{As}, \mathrm{Zn}$ are soil marker elements. Taking into account the fact that the study area originates from the ore body, therefore, the $\mathrm{Mo}$ and $\mathrm{Cu}$ concentrations are obviously identified in soil. The heavy metals concentrations increase due to anthropogenic soil transformation. Anthropogenically the most affected soils are of open pits and overburden rock dumps. The element concentrations increase due to the soil profile depth and its geological structure. The high element concentrations in the top soils are caused by aerogenic pollution owing to the pollutant transfer from the main anthropogenic sources.

\section{Key words:}

Soil, mining and processing industrial complex, field, heavy metals, inductively coupled plasma mass spectrometry, ecological and geochemical assessment.

The authors express gratitude to Galina E. Pashneva, Cand. Sc., for advice in description of soil section characteristics, to Nina V. Fedyunina, director of CAC «Plazma», for soil sample chemical analysis.

The research was carried our within the contract-based works with «Sorsk mining and processing industrial complex» (2015). The research was carried out at National Research Tomsk Polytechnic University within the Program of Enhancement TPU Competitiveness among the Leading World Research Centers.

\section{REFERENCES}

1. Basova I.A., Ioina M.A., Glukhova E.N. Geoekologicheskoe sostoyanie pochvennogo pokrova $\mathrm{v}$ gornopromyshlennykh regionakh [Geoecological condition of soil covers in mining regions]. Izvestiya TulGU, 2010, no. 1, pp. 16-20.

2. Basova I.A., Ivatanova N.P., Kopilov A.B. Otsenka ekologicheskogo sostoyaniya pochv $\mathrm{v}$ regionakh s razvitoy gornoy promyshlennostyu [Evaluation of soil environmental conditions in the regions with advanced mining industry]. Izvestiya TulGU, 2012, no. 1-2, pp. 14-16.
3. Korneeva T.V., Yurkevich N.V., Saeva O.P. Geochemical modeling of heavy metals behavior in technogenic systems. Bulletin of the Tomsk Polytechnic University. Geo Assets Engineering, 2018, vol. 329, no.3, pp. 89-101.

4. Kasimov N.S., Kosheleva N.E., Gunin P.D., Korlyakov I.D., Sorokina O.I., Timofeev I.V. State of the environment of urban and mining areas in the Selenga Transboundary River Basin (Mongolia Russia). Environmental Earth Sciences, 2016, vol. 75, Iss. 1283, pp. 1-20.

5. Yang Q., Li Z., Lu X., Duan Q., Huang L. A review of soil heavy metal pollution from industrial and agricultural regions 
in China: Pollution and risk assessment. Science of the total environment, 2018, vol. 642, pp. 690-700.

6. Du F., Yang Z., Liu P., Wang L. Accumulation, translocation, and assessment of heavy metals in the soil-rice systems near a mineimpacted region. Environmental science and pollution research, 2018, vol. 25 (32), pp. 32221-32230.

7. Ghazban F., Parizanganeh A., Zamani A., Baniardalan S. Evaluation of heavy metal contamination of surface soils in Zarshouran gold district, Northwestern Iran. International Journal of environmental research, 2018, vol. 12 (6), pp. 843-860.

8. Sawut R., Kasim N., Abliz A., Li H., Yalkun A., Maihemuti B., Shi Q.D. Possibility of optimized indices for the assessment of heavy metal contents in soil around an open pit coal mine area. International journal of applied earth observation and geoinformation, 2018 , vol. 73, pp. 14-25.

9. Midhat L., Ouazzani N., Hejjaj A., Ouhammou A., Mandi L. Accumulation of heavy metals in metallophytes from three mining sites (Southern Centre Morocco) and evaluation of their phytoremediation potential. Ecotoxicology and Environmental Safety 2019, vol. 169, pp. 150-160. Available at: https://doi.org/10.1016/ j.ecoenv.2018.11.009 (accessed 1 October 2019).

10. Martin C.W. Trace metal concentrations along tributary streams of historically mined areas, Lower Lahn and Dill River basins, central Germany. Catena, 2019, vol. 174, pp. 174-183. Available at: https://doi.org/10.1016/j.catena.2018.11.008 (accessed 1 October 2019).

11. Du Y., Chen L., Ding P., Chen B., Duan Y.Different exposure profile of heavy metal and health risk between residents near a $\mathrm{Pb}-\mathrm{Zn}$ mine and Mn mine in Huayuan county, South China. Chemosphere, 2019, vol. 216, pp. 352-364. DOI 10.1016/j.chemosphere.2018.10.142

12. Li L., Wu J., Lu J., Xu J., Yang L. Distribution, pollution, bioaccumulation, and ecological risks of trace elements in soils of the northeastern Qinghai-Tibet Plateau. Ecotoxicology and Environmental Safety, 2018, vol. 166, pp. 345-353.
13. Li F., Li X., Hou L., Shao A. Impact of the coal mining on the spatial distribution of potentially toxic metals in Farmland tillage soil. Scientific Reports, 2018, vol. 8 (1), pp. 14925.

14. Zhang J., Yao D. Geochemical characteristics and source analysis of soil heavy metals in Luling coal mine, northern Anhui Province. IOP Conference Series: Earth and Environmental Science, 2018, vol. 189 (3), pp. 032058.

15. Pevzner M.E., Kostoveckiy V.P. Ekologiya gornogo proizvodstva [Ecology of miming industry]. Moscow, Nedra Publ., 1990. 230 p.

16. Metodicheskie ukazaniya po otsenke stepeni opasnosti zagryazneniya pochvy himicheskimi veshchestvami [Guidelines on the assessment of soil pollution level bu chemical elements] no. 4266-87. Moscow, Ministry of public health service of USSR, 1987. $23 \mathrm{p}$.

17. GOST 17.4.4.02-84. Okhrana prirody. Pochvy. Metody otbora $i$ podgotovki prob dlya khimicheskogo, bakteriologicheskogo, gelmintologicheskogo analiza [Nature protection. Soils. Methods for sampling and preparation of soil for chemical, bacteriological, helmintological analysis]. Moscow, Standartinform Publ., 2008. 12 p.

18. GOST 17.4.3.01-83. Okhrana prirody (SSOP). Pochvy. Obshchie trebovaniya $k$ otboru prob [Nature protection. Soils. General requirements for sampling]. Moscow, Standartinform Publ., 2008. 12 p.

19. Saet Yu.E, Revich B.A., Yanin E.P. Geokhimiva okruzhayu shchey sredy [Geochemistry of the environment]. Moscow, Nedra Publ., 1990. $335 \mathrm{p}$.

20. Yazikov E.G., Shatilov A.Yu. Geoekologicheskiy monitoring [Geoecological assessment]. Tomsk, TPU Publ. house, 2004. 276 p.

21. Metodicheskie rekomendatsii po otsenke stepeni zagryazneniya atmosfernogo vozdukha naselennykh punktov metallami po ikh soderzhaniyu $v$ snezhnom pokrove $i$ pochve [Guidelines on the assessment of pollution level by metals deposited in soil and snow in settlements]. Eds. B.A. Revich, Yu.E. Saet, R.S. Smirnova. Moscow, IMGRE Publ., 1990. 7 p.

\section{Information about the authors}

Aleksandra V. Belosheykina, chief of ecology group, LLC «KHAKASTISIZ».

Anna V. Talovskaya, Cand. Sc., associate professor, National Research Tomsk Polytechnic University.

Egor G. Yazikov, Dr. Sc., professor, National Research Tomsk Polytechnic University. 